\title{
Job strain, job demands, decision latitude, and risk of coronary heart disease within the Whitehall II study
}

\section{H Kuper, M Marmot}

J Epidemiol Community Health 2003;57:147-153

See end of article for authors' affiliations .....................

Correspondence to: Hannah Kuper, Trachoma Initiative in Monitoring and Evaluation, Clinical

Research Unit, London School of Hygiene and Tropical Medicine, Keppel Street, London WC1E 7HT, UK:

hannah.kuper@|shtm.ac.uk

Accepted for publication 14 June 2002

\begin{abstract}
Study objectives: To investigate the association between job strain and components of the job strain model and coronary heart disease (CHD) risk.

Design: Prospective cohort study (Whitehall II study). At the first phase of the study (1985-1988), data on self reported psychosocial work characteristics were collected from all participants. Participants were followed up until the end of phase 5 (1997-2000), with mean length of follow up of 11 years. Setting: London based office staff in 20 civil service departments.

Participants: 6895 male and 3413 female civil servants aged 35-55.

Outcome measures: Incident validated CHD.

Main results: People with concurrent low decision latitude and high demands (job strain) were at the highest risk for CHD. High job demands, and, less consistently, low decision latitude, predicted CHD incidence. The effect of job strain on CHD incidence was strongest among younger workers, but there was no effect modification by social support at work, or employment grade.

Conclusions: Job strain, high job demands, and, to some extent, low decision latitude, are associated with an increased risk of CHD among British civil servants.
\end{abstract}

$\mathrm{T}$ he belief that stress at work has a damaging effect on health is widely held by the general public and various constructs have been developed to explain how the worker and job environment interact to produce stress. The most widely cited of these models is the Karasek-Theorell job strain model, the two central components of which are high job demands (the need to work quickly and hard) and low decision latitude (lack of control over skill use, time allocation and organisational decisions). ${ }^{12}$ The theory purports that workers who have concurrent low decision latitude and high demands cannot moderate the stress caused by the high demands through time management or learning new skills, and so become subject to high stress at work and are at increased risk of disease. It is therefore the constraints on decision making, together with high demands, which produce the unhealthy condition of stress at work, or "job strain".

The job strain model was initially used to explain patterns of depression, exhaustion, and job dissatisfaction, ${ }^{1}$ but was later expanded to include cardiovascular disease (reviewed by Schnall ${ }^{3}$ and Hemingway ${ }^{4}$ ), poor health functioning, ${ }^{5}$ and sickness absenteeism. ${ }^{6}$ As the literature has accumulated, the model has been refined. The iso-strain model argues that job strain is particularly deleterious for people with low social support at work, as adequate social networks can buffer the effects of job strain..$^{7-9}$ Similarly, high income and the availability of tangible resources may reduce the effect of job strain on health, hence strain might be more deleterious among workers with low socioeconomic status (SES) ${ }^{7810}$ and in younger age groups. ${ }^{11-13}$

The early results from the Whitehall II study were promising, finding that low decision latitude, whether through self report or independent assessment, predicted self reported incident coronary heart disease $(\mathrm{CHD})^{14}$ and higher rates of short term and long term sickness absence. ${ }^{15}$ In fact, adjusting for low decision latitude reduced the odds of development of any CHD in the lowest compared with the highest grade from 1.5 to $1.2 .{ }^{16}$ Moreover, both high psychological demands and low decision latitude predicted higher rates of psychiatric disorder, ${ }^{17}$ and in women high demands predicted poor health functioning. ${ }^{18}$
Our purpose in this paper is to extend these earlier analyses to investigate the role of the full job strain model, that is simultaneous low decision latitude and high psychological job demands, in relation to validated incident CHD events including an extra six years of follow up compared with previous reports. ${ }^{14}$ As subsidiary analyses we will investigate the effect of the individual components of the model, that is decision latitude and job demands, on risk of CHD. We will attempt to clarify the role of social position and traditional coronary risk factors in driving the association between work characteristics and CHD risk. Furthermore, we will test for effect modification, as we hypothesise that the health effects of job strain will be more pronounced in people with low social support at work, lower employment grades, lower father's social class, and of younger age.

\section{METHODS}

\section{Study population}

Full details of the study are reported elsewhere. ${ }^{19}$ Briefly, the Whitehall II study is a new cohort of civil servants that was established between 1985 and 1988 (phase 1). All nonindustrial civil servants aged 35-55 working in the London offices of 20 departments were sent an introductory letter and screening questionnaire, and were offered a screening examination for cardiovascular disease. The overall response rate was $73 \%$ ( $74 \%$ for men, $71 \%$ for women), but the true response rate was probably higher, as about $4 \%$ of the civil servants on the lists provided by the civil service had moved before the study and were therefore ineligible for inclusion. In total, 10308 civil servants participated, of whom 67\% (6895) were men and 33\% (3413) were women. Participants were approached again in 1989-90 (phase 2: postal questionnaire, 8129 respondents), in 1991-93 (phase 3: postal questionnaire and screening examination, 8548 respondents), in 1995 -96 (phase 4: postal questionnaire, 8700 respondents) and 1997-99 (phase 5: postal questionnaire, and screening examination, 7830 respondents). The length of follow up from phase 1 to phase 5 was a median of 11.2 years (range 
9.1-13.8). Written informed consent for participation in the study was obtained from the subjects as part of the questionnaire.

\section{Coronary heart disease events}

Altogether $10300(99.9 \%)$ participants were flagged at the National Health Service Central Registry, who notified us of the date and cause of death. Participants were defined as having a coronary death if the underlying cause had an ICD-9 code $410-414 .{ }^{20}$ Potential non-fatal myocardial infarction (MI) and angina events were ascertained by questionnaire items on: chest pain (the World Health Organisation Rose questionnaire), ${ }^{21}$ recall of a doctor's diagnosis, investigation (exercise electrocardiography, stress imaging, or angiography), and treatment (nitrates or revascularisation). Details of physician diagnoses and investigation results were sought from clinical records for all potential cases of MI and angina. Twelve lead resting electrocardiograms were performed at study phases 1, 3, and 5 (Simmons Mingorec) and classified according to the Minnesota code. ${ }^{2122}$ Classification of MI and angina was carried out independently by two trained coders, with adjudication by a third in the (rare) event of disagreement.

\section{Demographic and socioeconomic characteristics}

Information on demographic characteristics was obtained from a self completed questionnaire at baseline. Within the Whitehall II study civil service employment grade provides an excellent measure of SES. Administrative grades were condensed into six categories, in order of decreasing salary this consisted of unified grades 1 through 6 (permanent secretary through senior principal); unified grade 7 (principal); senior executive officer; higher executive officer; executive officer; and clerical officer, clerical assistant, and office support staff. Professional and technical staff were classified with administrative grades with equivalent salaries. However, as grade is an occupational characteristic, grade and work characteristics are highly collinear; the correlation between decision latitude and grade was 0.51 in men and 0.55 in women, and the correlation between job demands and grade

Table 1 Mean baseline job control (decision latitude) and job demands for each category of demographic, socioeconomic, and health behaviour characteristics

\begin{tabular}{|c|c|c|c|c|}
\hline & \multicolumn{2}{|l|}{ Men } & \multicolumn{2}{|l|}{ Women } \\
\hline & Job control & Job demands & Job control & Job demands \\
\hline \multicolumn{5}{|l|}{ Age (y) } \\
\hline$\geqslant 39-<45$ & $67.0(14.6)$ & $59.9(19.5)$ & 61.5 (16.9) & $56.1(20.2)$ \\
\hline$\geqslant 45-<50$ & $68.9(14.8)$ & $61.3(20.1)$ & $58.5(16.8)$ & $54.2(20.7)$ \\
\hline$\geqslant 50-<55$ & $69.4(14.8)$ & 60.5 (19.4) & $56.2(18.0)$ & $51.6(20.9)$ \\
\hline$\geqslant 55-<64$ & $68.6(15.7)^{\text {* * }}$ & $59.0(20.7)^{\text {* * }}$ & $53.8(18.2)^{* *}$ & $49.6(20.4)^{* *}$ \\
\hline Administrative & $75.5(10.9)$ & $66.9(18.3)$ & $74.6(11.4)$ & $67.9(18.2)$ \\
\hline Professional & 66.9 (12.9) & $58.1(18.8)$ & $64.1(14.0)$ & $58.0(18.7)$ \\
\hline Clerical & $46.5(17.0)^{* *}$ & $44.3(20.8)^{* *}$ & $47.7(16.1)^{* *}$ & $44.8(19.4)^{* *}$ \\
\hline Non-home owner & $55.5(18.9)$ & $51.1(22.1)$ & $49.8(17.6)$ & $46.4(20.3)$ \\
\hline Home owner & $69.4(14.1)^{\text {** }}$ & $60.9(19.6)^{\text {** }}$ & $59.2(17.4)^{* *}$ & $54.3(20.4)^{\text {** }}$ \\
\hline Car owner & $69.8(14.1)$ & $61.1(19.6)$ & $58.5(17.4)$ & $53.3(20.6)$ \\
\hline Non-car owner & $60.2(17.0)^{* *}$ & $55.2(21.2)^{\text {** }}$ & $54.0(18.5)^{* *}$ & $51.0(20.8)^{* *}$ \\
\hline Never smoker & $68.7(14.7)$ & $60.6(19.8)$ & $57.5(17.8)$ & $52.3(21.0)$ \\
\hline Former smoker & 69.5 (14.6) & 60.3 (19.7) & $58.7(17.6)$ & $53.8(20.6)$ \\
\hline Current smoker 1-10 & 64.8 (15.9) & $57.2(20.2)$ & $55.8(18.5)$ & $53.2(20.3)$ \\
\hline Current smoker $11-20$ & $64.9(15.7)$ & $58.8(19.9)$ & $54.7(17.9)$ & 50.5 (19.9) \\
\hline Current smoker $\geqslant 20$ & $66.9(16.3)^{* *}$ & $62.1(20.5)^{\text {* * }}$ & $56.1(17.4)^{* *}$ & $54.6(21.2)$ \\
\hline Non-drinker & $64.1(16.8)$ & $56.0(20.8)$ & $53.2(17.4)$ & $48.9(20.6)$ \\
\hline Below limit & $69.0(14.6)$ & $60.8(19.6)$ & $58.5(17.7)$ & $53.7(20.5)$ \\
\hline Above limit & $68.7(14.3)^{\text {* * }}$ & $60.8(20.2)^{\text {** }}$ & $64.7(17.7)^{* *}$ & $61.2(20.6)^{* *}$ \\
\hline$<1.5 \mathrm{~h}$ exercise/wk & $65.3(16.6)$ & $57.9(21.5)$ & $55.6(18.3)$ & $50.7(20.9)$ \\
\hline$\geqslant 1.5 \mathrm{~h}$ exercise/wk & $69.7(14.0)^{* *}$ & $61.2(19.1)^{* *}$ & $58.8(17.1)^{* *}$ & $54.5(20.4)^{\text {** }}$ \\
\hline$<20 \mathrm{BMI}$ & $64.1(15.5)$ & $57.7(19.1)$ & $60.6(17.0)$ & $56.9(21.5)$ \\
\hline $20-24.99$ & 68.8 (14.9) & 60.5 (19.8) & 57.7 (17.9) & $52.6(20.8)$ \\
\hline $25-29.99$ & $68.5(15.4)$ & $60.1(20.2)$ & $55.9(17.3)$ & $51.3(20.4)$ \\
\hline$\geqslant 30$ & $66.2(16.2)^{* *}$ & $59.1(20.4)$ & $55.5(18.6)^{* *}$ & $53.0(19.7)^{* *}$ \\
\hline No hypertension & $68.5(14.9)$ & $60.4(19.9)$ & $57.5(17.7)$ & $52.8(20.8)$ \\
\hline Hypertension & $67.0(16.1) *$ & $57.6(19.6)$ ** & $54.0(18.9)^{* *}$ & $50.1(19.8)^{*}$ \\
\hline Low job control & - & $51.9(21.2)$ & - & 46.8 (19.9) \\
\hline Medium job control & - & $60.3(18.9)$ & - & $56.5(19.8)$ \\
\hline High job control & - & $65.1(18.2)^{* *}$ & - & $62.9(18.4)^{* *}$ \\
\hline Low job demands & 61.8 (17.0) & - & $50.8(17.5)$ & - \\
\hline Medium job demands & $69.0(14.0)$ & - & $59.8(16.3)$ & - \\
\hline High job demands & $72.5(12.9)^{\text {* * }}$ & - & $64.9(17.0)^{* *}$ & - \\
\hline Low support at work & $64.2(16.5)$ & $61.4(20.6)$ & $52.8(18.5)$ & $53.8(21.7)$ \\
\hline Medium support work & $69.3(13.9)$ & $60.7(19.6)$ & $58.8(17.1)$ & $54.1(19.7)$ \\
\hline High support at work & $71.5(13.4)^{\text {** }}$ & $58.4(19.4)^{* *}$ & $61.0(16.4)^{* *}$ & $50.1(20.1)^{* *}$ \\
\hline
\end{tabular}




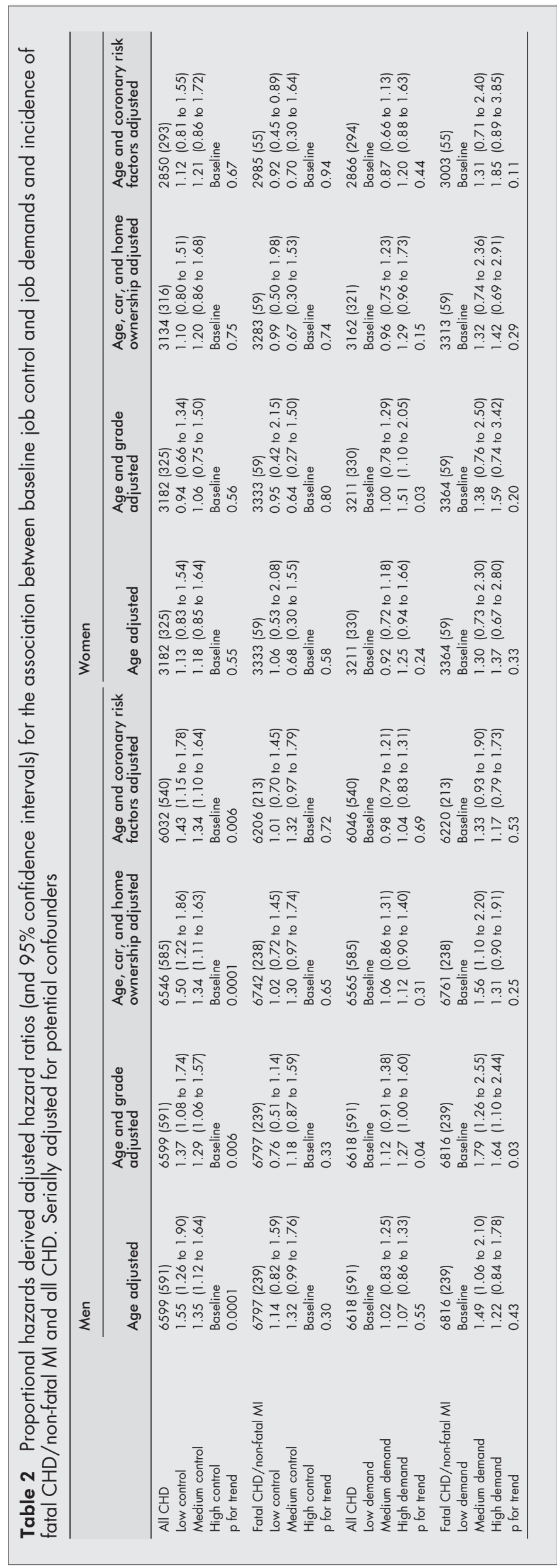

was 0.32 in men and 0.40 in women. This means that adjustment for grade may be over-adjustment when evaluating the association between work characteristics and CHD incidence. It might therefore be necessary to adjust for markers of SES other than employment grade. For this reason information on other SES related factors were also collected, including access to a car and home ownership. The correlation between decision latitude and home and car ownership, respectively, is lower than the correlation between decision latitude and employment grade, in both men ( $r=0.24$ for home ownership, $r=0.22$ for car ownership) and women $(0.22,0.11)$. Similarly, the correlation between job demands and home and car ownership was lower than the correlation with grade in both men $(0.13,0.10)$ and women $(0.16,0.05)$.

\section{Psychosocial work characteristics}

Work characteristics were measured at baseline through self administered questionnaire. The self report items were derived from well known questionnaires for the central components of the job strain model, that is, psychological job demands, decision latitude, and social support at work (see appendix). ${ }^{14}$ A measure of physical job demands was considered inappropriate for this white collar population, and therefore was not included. Four items dealt with psychological job demands, and 15 items dealt with decision authority and skill discretion, which were combined into an index of decision latitude (or job control). ${ }^{14}$ Scores for each scale were calculated as the sum of the item scores and all scales were divided into tertiles. The few subjects missing one item in a scale were assigned an average score based on the items that they did answer. Four quadrants of job strain (high demand and high decision latitude; high demand and low decision latitude; low demand and high decision latitude; low demand and low decision latitude) were constructed, by cross tabulating job demands and decision latitude, both divided in two groups at the median.

\section{Traditional coronary risk factors}

Data on classic coronary risk factors were measured in standard ways at the baseline questionnaire. ${ }^{19}$ Coronary risk factors included: cigarette smoking ("never smokers", "ex smokers", and "current smokers": $\leqslant 10,11-20$, or $>20$ cigarettes/day'), serum cholesterol (mmol/l), hypertension (diastolic blood pressure $\geqslant 95 \mathrm{~mm} \mathrm{Hg}$, systolic blood pressure $\geqslant 160 \mathrm{~mm} \mathrm{Hg}$ or drug treatment for hypertension), exercise ( $\geqslant 1.5$ or $<1.5$ hours of moderate or vigorous exercise per week), alcohol consumption (non-drinker, drink at or below the recommended limit set by the British Department of Health, drink above the recommended limit), and body mass index (BMI) (BMI $<20,20-24.9,25-29.9, \geqslant 30$ $\mathrm{kg} / \mathrm{m}^{2}$ ).

\section{Statistical analysis}

The mean and standard deviations of self reported decision latitude and job demand scores were calculated for each category of baseline variables, separately for men and women. Analysis of variance was used to test for significant differences in means.

Survival analyses were conducted to determine whether baseline decision latitude, job demands, and social support at work, in turn, predicted age adjusted incident CHD during follow up, stratified by gender. The models were successively adjusted for employment grade, other SES indicators, and traditional coronary risk factors.

Next, again through survival analyses, the four job strain quadrants were modelled against CHD events. Totest for a significant interaction between high job 
Table 3 Proportional hazards derived adjusted hazard ratios (and 95\% confidence intervals) for the association between baseline job strain and incidence of fatal CHD/non-fatal MI and all CHD. Serially adjusted for potential confounders

\begin{tabular}{|c|c|c|c|c|c|}
\hline & Age and sex adjusted & $\begin{array}{l}\text { Age, sex, and grade } \\
\text { adjusted }\end{array}$ & $\begin{array}{l}\text { Age, sex, and SES } \\
\text { adjusted }\end{array}$ & $\begin{array}{l}\text { Age, sex, and } \\
\text { coronary risk factors } \\
\text { adjusted }\end{array}$ & $\begin{array}{l}\text { Age, sex, grade, and } \\
\text { coronary risk factors } \\
\text { adjusted }\end{array}$ \\
\hline All CHD & $9746(910)$ & 9746 (910) & $9646(895)$ & $8851(828)$ & $8851(828)$ \\
\hline Low demand high control & Baseline & Baseline & Baseline & Baseline & Baseline \\
\hline High demand low control & 1.57 (1.26 to 1.96$)$ & 1.49 (1.19 to 1.86$)$ & 1.55 (1.24 to 1.94$)$ & 1.42 (1.13 to 1.80$)$ & 1.38 (1.10 to 1.75$)$ \\
\hline Low demand low control & $1.25(1.00$ to 1.56$)$ & $1.12(0.88$ to 1.41$)$ & 1.19 (0.95 to 1.49 ) & $1.21 \quad(0.96$ to 1.52$)$ & 1.17 (0.92 to 1.49$)$ \\
\hline High demand high control & $1.17(0.94$ to 1.45$)$ & 1.26 (1.02 to 1.57$)$ & 1.16 (0.94 to 1.44$)$ & $1.15(0.92$ to 1.43$)$ & $1.20(0.95$ to 1.50$)$ \\
\hline$p$ for interaction & 0.59 & 0.71 & 0.43 & 0.85 & 0.96 \\
\hline Fatal CHD/ non-fatal MI & 10095 (296) & 10095 (296) & 9991 (295) & $9160(266)$ & $9160(266)$ \\
\hline Low demand high control & Baseline & Baseline & Baseline & Baseline & Baseline \\
\hline High demand low control & $1.42(0.99$ to 2.05$)$ & $1.25(0.87$ to 1.82$)$ & 1.36 (0.94 to 1.97$)$ & $1.22(0.83$ to 1.80$)$ & $1.16(0.78$ to 1.71$)$ \\
\hline Low demand low control & $0.90(0.60$ to 1.33$)$ & $0.67(0.44$ to 1.01$)$ & 0.84 (0.56 to 1.25$)$ & $0.81 \quad(0.54$ to 1.22$)$ & $0.71(0.46$ to 1.10$)$ \\
\hline High demand high control & $1.11(0.79$ to 1.56$)$ & $1.27(0.89$ to 1.80$)$ & $1.13(0.80$ to 1.60$)$ & $1.07(0.75$ to 1.54$)$ & $1.14(0.79$ to 1.65$)$ \\
\hline$p$ for interaction & 0.15 & 0.12 & 0.15 & 0.19 & 0.18 \\
\hline
\end{tabular}

demands and low decision latitude on the multiplicativescale in predicting CHD events, an interaction term for job demand and decision latitude was introduced into a regression model along with the main components (that is, high job demands and low decision latitude). These models were also successively adjusted for employment grade, other SES indicators and traditional coronary risk factors. The analyses were stratified, in turn, by social support at work, grade (at three levels), age (four age groups), and father's social status (at four levels).

All analyses were performed on complete datasets using the statistical package SAS. Dummy indicators represented ordinal variables, such as employment grade level, in the analyses. Tests for trends were performed by modelling the group scores of psychosocial work variables $(1,2,3)$ as one variable. As we are testing a number of hypotheses the level of statistical significance will be $\mathrm{p} \leqslant 0.01$.

\section{RESULTS}

Job demand and decision latitude generally had the same relation with the baseline variables (table 1). Men reported higher decision latitude and job demands than women, as did people in higher SES, whether measured through employment grade or home ownership and car ownership. Nonsmokers were more likely to claim they had high decision latitude, whereas heavy smokers were more likely to report high job demands. For the rest, healthy lifestyle variables were related to high demands and high decision latitude, excepting alcohol consumption, which was generally highest in the people with high decision latitude and demands. Decision latitude and job demands were positively correlated, whereas high social support at work was associated with high decision latitude and with low job demands. Overall $22 \%$ of participants were in the job strain group, that is concurrently below the median for decision latitude and above the median for job demands. This figure was slightly, but significantly higher in women than in men $(24.7 \%$ versus $20.7 \%, p<0.01)$. Some $11.2 \%$ of men had both low decision latitude and job strain, compared with $16.9 \%$ of women. Furthermore, $9.1 \%$ of men had both high job demands and job strain, compared with $9.4 \%$ of women.

In men (table 2), low decision latitude was a significant predictor of all CHD (hazard ratio (HR) for low decision latitude $1.55,95 \%$ CI 1.26 to $1.90, \mathrm{p}$ for trend 0.0001 ), and some increase in risk of fatal CHD/non-fatal MI was apparent. In women, the presence of an association between low decision latitude and risk for CHD was less evident. Adjusting for grade somewhat reduced the strength of the association between decision latitude and all CHD in men, although both the effect estimates and trend remained significant. Adjustment for grade may be over-adjustment, hence associations were also analysed net of other SES indicators, and this had little effect on the associations. Although some confounding by coronary risk factors was apparent, neither the effect estimates nor trend in the association between decision latitude and all CHD lost significance.

The effect of high demands on CHD events was most apparent for fatal CHD/non-fatal MI in both men and women, although there was also some increase in risk of all CHD. The associations became stronger after adjustment for grade. The grade adjusted risk in the groups with highest demands were apparent for all CHD in both men (HR 1.27, 95\% CI 1.00 to 1.60 ) and women (HR 1.51, 95\% CI 1.10 to 2.05) and fatal CHD/non-fatal MI in men (HR 1.64, 95\% CI 1.10 to 2.44 ). Adjusting for other SES variables strengthened the association between demand and CHD events somewhat, but including traditional coronary risk factors in the model had little effect. There was no apparent association between social support at work and CHD events, in either men or women, with or without adjustment for grade level (data not shown).

There was no significant interaction by sex in the relation between job strain and CHD events, and so the following analyses were adjusted for, rather than stratified by, gender. People with job strain consistently had the highest risk for both categories of CHD events during follow up (table 3). In the age and sex adjusted analyses those with job strain had significantly increased risk for all CHD (HR 1.57, 95\% CI 1.26 to 1.96) and increased risk of fatal CHD/non-fatal MI (HR $1.42,95 \%$ CI 0.99 to 2.05 ). Adjustment for grade diminished the effect of job strain on CHD events. The effect of job strain on CHD events was relatively unchanged net of other indicators of SES, but adjustment for coronary risk factors did weaken the associations. The final model, which included both grade and coronary risk factors, demonstrated a statistically significant increased risk for all CHD among those with job strain (HR 1.38, 95\% CI 1.10 to 1.75 ), but little association with fatal CHD/non-fatal MI remained. There was no evidence of statistical interaction between low decision latitude and high demand in their relation to all CHD events or fatal CHD/ non-fatal MI.

There was no evidence of a strengthened effect of job strain in people who reported low social support at work for either CHD outcome (table 4). Job strain seemed, if anything, to be most deleterious with respect to risk of all CHD among administrative workers, which is in contrast with our hypotheses. Stratifying on age at entry showed that job strain was most closely related to CHD risk in the youngest age group. There was no apparent difference in the association between 


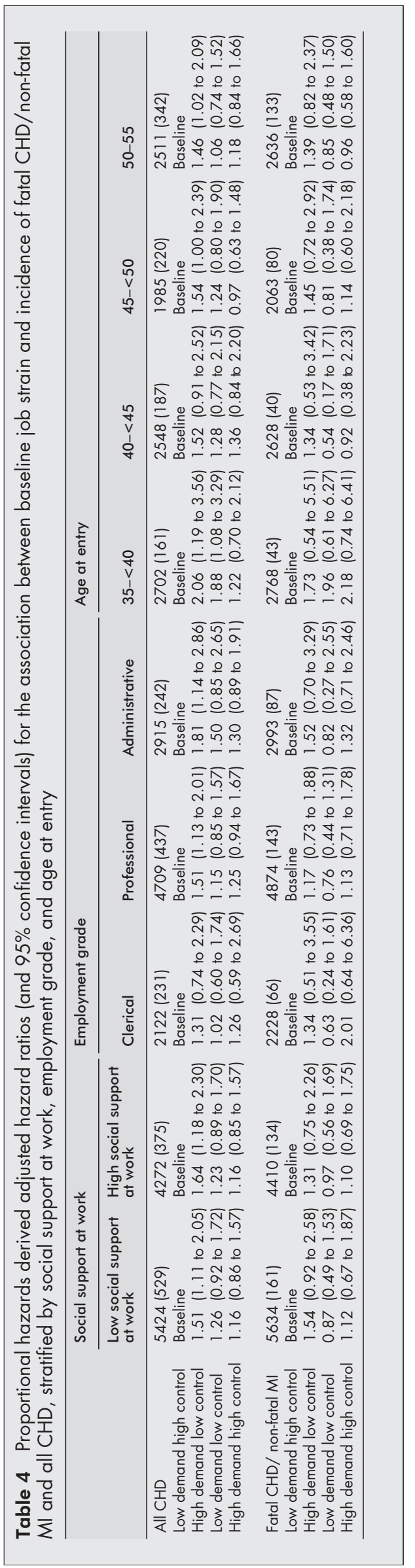

\section{Key points}

- People with job strain are at increased risk for coronary heart disease.

- People with high demands, and to a lesser extent, low control, are at increased risk for heart disease.

- As the prevalence of job strain is high the potential impact on population health is great.

- Policy implications of this research are that strategies for work place health promotion could rely on redesigning jobs by reducing psychological demands and increasing control at work.

- Intervention studies to evaluate the effect of reducing job strain are timely and necessary to assess the potential utility of implementing policy changes.

job strain and CHD events in strata of father's social class (data available on request). None of these interactions reached statistical significance.

\section{Discussion}

The combination of high job demands and low decision latitude, that is job strain, was associated with risk of CHD events, net of markers of SES and health behaviours, although the interaction between low decision latitude and high demands was not statistically significant. High demands were related to future occurrence of all CHD, especially fatal CHD/non-fatal MI for both men and women, whereas low decision latitude was predictive only of all CHD in men. The association with decision latitude persisted, and with demands became stronger, after adjustment for employment grade or other indicators of SES. Furthermore, although traditional coronary risk factors confounded these associations, they could not entirely explain the relation. As hypothesised, the effect of job strain was stronger among younger participants, but there was no apparent effect of social support at work, employment grade, or father's social class.

These results are largely consistent with previous findings from the Whitehall II study, where high decision latitude, whether assessed objectively or subjectively, protected from future CHD. ${ }^{14}$ However, high job demands seemed to be a more important predictor of CHD events than was apparent based on the earlier phases of the study, perhaps because we have used more comprehensive adjustment for the effects of grade and so reduced the effects of positive confounding by grade. Our present finding is supported by many published studies that both high demand and low decision latitude and job strain are associated with increased risk of CHD. ${ }^{3423}$ The similarity in these associations between men and women is consistent with the findings of the review by Schnall. ${ }^{3}$ Moreover, our results do not give credence to the iso-strain hypothesis, ${ }^{7-9}$ that is the model that the effects of job strain are most deleterious in people with low social support at work, because these people are lacking resources that could help buffer the harmful effects of a stressful work environment. Our results do, however, support the idea that the effect of job strain is in younger age groups. ${ }^{11-13}$ These findings are also at odds with earlier reports that the effect of job strain was more deleterious among lower SES, ${ }^{8}{ }^{10}$ as neither present nor childhood SES seemed to be important effect modifiers.

\section{Possible explanations}

Chance is an unlikely explanation for our findings, as the association with incidence of CHD was apparent for both high demands and low decision latitude, and additionally, the effect was found in both men and women. Selection bias could be a possible explanation if it can be argued that more susceptible people choose to work in high strain jobs. However, this is counter-intuitive as people at high risk for CHD are unlikely to choose stressful jobs, and people with preclinical disease may 
actually switch to less hectic jobs. ${ }^{24}$ Self report bias, or negative affectivity, is unlikely to be important because validated events were used as our outcome variables and the study design was prospective. Bias attributable to loss to follow up is also improbable, as the rate of follow up was high and adjusting for leaving the civil service did not affect the associations (data not shown).

Of course we cannot claim to have eliminated entirely the effect of confounding, but as adjustment for traditional CHD risk factors did not reduce the associations substantially uncontrolled confounding by these risk factors is unlikely to fully explain our findings. Furthermore, because deleterious health behaviours may be part of the causal pathway by which adverse psychosocial work characteristics influence CHD risk, adjustment for these variables may be over-adjustment. Confounding of the associations between psychosocial work characteristics and CHD events by other psychosocial variables, suggested by other researchers, ${ }^{25}$ is unlikely in this setting, because in in the Whitehall II study psychological attributes, including hostility, negative affectivity, and minor psychiatric disorders, could not explain the association between low decision latitude and CHD events. ${ }^{26}$

In most occupational cohorts job strain is a more common condition in lower employment grades and this could partly explain the social gradient in health. Within Whitehall II, low decision latitude is indeed more common in the lower employment grades, but high demands are usually found in the highest employment grades. This creates a fundamental problem of whether or not to adjust for grade, as adjusting for employment grade could be over-adjustment with respect to decision latitude, but necessary with respect to job demands. As a compromise other measures of SES were adjusted for, that is car and home ownership, because this would allow the confounding effect of SES to be reduced, yet these variables are less highly colinear with work characteristics. As adjustment for grade was probably over-adjustment with respect to decision latitude, yet some association with future CHD events persisted, it is unlikely that the association merely reflects the effect of social position on CHD risk.

The association between job strain and CHD may be true and causal. Adverse work characteristics can induce biological arousal through neuroendocrine mechanisms affecting blood lipids $^{27}$ and blood fibrinogen ${ }^{27}$ and increasing blood pressure, ${ }^{29-31}$ or neuroendocrine mechanisms that increase catecholamines and cortisol. ${ }^{32}{ }^{33}$ An increased left ventricular mass index has also been noted in men with high job strain. ${ }^{30}$ Moreover, job strain could exert its influence on CHD risk through modification of future coronary risk factors, such as the uptake of smoking or failure to adhere to medical regimens. ${ }^{34-36}$ Furthermore, taking analogy from other emotionally stressful events, job strain could acutely trigger coronary events in vulnerable people in the final stages of $\mathrm{CHD} .^{37}$

\section{Study strengths}

This study was large and had extended follow up. The study had a prospective design and investigated only validated incident CHD among people who were disease free at baseline, excluding the possibility of recall bias. Furthermore, we used valid and reliable measures of disease outcomes, minimising the potential for information bias. Both men and women were included in this cohort, as was a representative sample of workers from different employment grades. Information on psychosocial work characteristics was obtained through self report, rather than assigning scores based on job description, hence the score more accurately represents a person's work environment. Subjective assessment of work characteristics may further be preferable to objective assessment, because perceptions of the work environment may impact on health over and above the effect of actual work conditions.

\section{Study limitations}

It could be argued that as the Whitehall II population is organisationally specific it is difficult to make inferences to other populations. However, the previous findings from the Whitehall II study in relation to the effects of psychosocial factors on CHD events were closely in line with the findings from other similar studies. ${ }^{4}$ Furthermore, the study participants came from a range of social classes. We investigated the effect of work characteristics measured at only one point in time, so there is room for misclassification of the exposure variable. However, as the correlation between work characteristics measured at phases 1, 2, 3, and 5 is high (data not shown) and any misclassification is likely to be nondifferential, any bias will be small and towards the null.

There are specific limitations of the job strain model. High demands and low decision latitude are the only measures of pressure at work included, so other potential sources of stress, such as low pay, hazardous conditions, or job insecurity, are ignored. Furthermore, Siegrist and his colleagues argued that stress at work depends not on specific job task characteristics alone, but also on individual attributes that influence the ability to cope. ${ }^{38} \mathrm{Job}$ strain does not influence risk of CHD in all studies, ${ }^{39-41}$ possibly because of methodological differences in the design of the studies and the measures of job strain used. In addition, any investigation into the effects of work characteristics must be limited to people with jobs, and so there is a potential for bias through the healthy worker effect. The question of whether investigations on job strain and CHD are generalisable to non-working populations and aspects of life outside of work, however, and whether this may explain part of the social gradient in CHD in people who are not working, could be fruitfully explored in the future.

\section{Conclusions}

Job strain is associated with an increased risk of CHD among men and women employed in the civil service. The separate components of this model, job demands, and to a lesser extent decision latitude, also predicted incidence of CHD. These associations cannot be entirely explained by confounding by SES or traditional coronary risk factors. This research adds to a body of data showing an effect of deleterious psychosocial work characteristics on health. Specifically, the results of this research suggest that policies reducing psychological demands on workers may contribute to better cardiovascular health, particularly in women. In addition, giving people a stronger say in decisions about their work, providing them with more variety in work tasks or developing leadership may improve long term health. Therefore we can focus the strategies for work place health promotion on redesigning jobs, as well as identifying high risk people, such as those with job strain. Intervention studies to evaluate the effect of reducing job strain are therefore timely and necessary to assess the potential utility with respect to improving health of implementing policy changes.

\section{ACKNOWLEDGEMENTS}

We thank all participating civil service departments and their welfare, personnel, and establishment officers; the Occupational Health and Safety Agency; the Council of Civil Service Unions; all participating civil servants in the Whitehall II study; and all members of the Whitehall II study team.

\section{APPENDIX \\ Job demands}

Do you have to work very fast?

Do you have to work very intensively?

Do you have enough time to do everything?

Do different groups at work demand things from you that you think are hard to combine?

\section{Skill discretion}

Do you have the possibility of learning new things through your work? 
Does your work demand a high level of skill or expertise? Does your job require you to take the initiative? Do you have to do the same thing over and over again? Does your job provide you with a variety of interesting things? Is your job boring?

\section{Decision authority}

Do you have a choice in deciding HOW you do your work?

Do you have a choice in deciding WHAT you do at work?

Others take decisions concerning my work.

I have a good deal of say in decisions about work.

I have a say in my own work speed.

My working time can be flexible.

I can decide when to take a break.

I have a say in choosing with whom I work.

I have a great deal of say in planning my work environment.

\section{Social support at work}

Do you get sufficient information from line management (your superiors)?

Do you get consistent information from line management (your superiors)?

How often do you get help and support from your colleagues?

How often are your colleagues willing to listen to your work related problems?

How often do you get help and support from your immediate superior?

How often is your immediate superior willing to listen to your problems?

\section{Authors' affiliations}

H Kuper, M Marmot, International Centre for Health and Society, Department of Epidemiology and Public Health, University College London, London, UK

Funding: The Whitehall II study has been supported by grants from the Medical Research Council; British Heart Foundation; Health and Safety Executive; Department of Health; National Heart Lung and Blood Institute (HL36310), US, NIH: National Institute on Aging (AG13196), US, NIH: Agency for Health Care Policy Research (HSO6516); and the John D and Catherine T MacArthur Foundation Research Networks on Successful Midlife Development and Socio-economic Status and Health. MM is supported by an MRC Research Professorship.

Conflicts of interest: none.

\section{REFERENCES}

1 Karasek RA. Job demands, job decision latitude, and mental strain implications for job redesign. Administrative Science Quarterly 1979;24:285

2 Karasek RA, Theorell T. Healthy work: stress, productivity and the reconstruction of working life. New York: Basic Books, 1990.

3 Schnall PL, Landsbergis PA, Baker D. Job strain and cardiovascular disease. Annu Rev Public Health 1994;15:381-411.

4 Hemingway $\mathbf{H}$, Marmot $M$. Evidence based cardiology. Psychosocial factors in the aetiology and prognosis of coronary heart disease: a systematic review of prospective cohort studies. BMV 1999;318:460-7.

5 Cheng Y, Kawachi I, Coakley EH, et al. Association between psychosocial work characteristics and health functioning in American women: prospective study. BM 2000;320:1432-6.

6 Vahtera J, Kivimaki M, Pentti J, et al. Effect of change in psychosocial work environment on sickness absence: a seven year follow up of initially health employees. J Epidemiol Community Health 2000;54:484-93.

7 Johnson JV and Hall EM. Job strain, work place, social support and cardiovascular disease. Am J Public Health 1988;78:1336.

8 Johnson JV, Hall EM, Theorell T. Combined effects of job strain and social isolation on cardiovascular morbidity and mortality in a random sample of the Swedish male working population. Scand J Environ Health 1989;15:271-9.

9 Falk A, Hanson BS, Isacsson S-O, et al. Job strain and mortality in elderly men: social network, support, and influence as buffers. Am J Public Health 1992;82:1136-9.
10 Lynch J, Krause N, Kaplan GA et al. Workplace conditions, socioeconomic status, and the risk of mortality and acute myocardial infarction: the Kuopio Ischemic Heart Disease Risk Factor Study. Am J Public Health 1997;87:617-22.

11 Alfredsson L, Karasek R, Theorell T. Myocardial infarction and psychosocial work environment: an analysis of the male Swedish working force. Soc Sci Med 1982;16:463-7.

12 Alfredsson L, Spetx C-L, Theorell T. Type of occupation and near-future hospitalization for myocardial infarction and some other diagnoses. Int $J$ Epidemiol 1985; 14:378-88

13 Hammar N, Alfredsson L, Theorell T. Job characteristics and the incidence of myocardial infarction. Int J Epidemiol 1994;23:277-84.

14 Bosma $\mathbf{H}$, Marmot MG, Hemingway $\mathrm{H}$, et al. Low job control and risk of coronary heart disease in the Whitehall II (prospective cohort) study. BM 1997;314:558-65

15 North FM, Syme SL, Feeney A, et al. Psychosocial work environment and sickness absence among British civil servants: the Whitehall II study. Am J Public Health 1996;86:332-40.

16 Marmot MG, Bosma H, Hemingway $\mathrm{H}$, et al. Contribution of job control and other risk factors to social variations in coronary heart disease incidence. Lancet 1997;350:235-9.

17 Stansfeld SA, North FM, White I, et al. Work characteristics and psychiatric disorder in civil servants in London. J Epidemiol Community Health 1995;49:48-53.

18 Stansfeld SA, Bosma H, Hemingway $H$, et al. Psychosocial work characteristics and social support as predictors of SF-36 health functioning: the Whitehall II study. Psychosom Med 1998:60:247-55.

19 Marmot MG, Davey Smith G, Stansfeld S, et al. Health inequalities among British civil servants: the Whitehall Il study. Lancet 1991;337:1387-93

20 World Health Organisation. International classification of diseases-9th revision. Geneva: WHO, 1977.

21 Rose GA, Blackburn H, Gillum RF, et al. Cardiovascular survey methods. 2 edn. Geneva: WHO, 1982

22 Macfarlane P. Methodology of ECG interpretation in the Glasgow program. Meth Inform Med 1990;29:354-61.

23 Sacker A, Bartley M, Frith D, et al. The relationship between job strain and coronary heart disease: evidence from an English sample of the working male population. Psychol Med 2001:31:279-90.

24 Karasek RA, Schwartz JE, Theorell T. Stress and work and cardiovascular disease. Mimeograph. Dept of Industrial Engineering and Operations Research. New York: Columbia University, 1982

25 Williams RB, Barefoot JC, Blumenthal JA, et al. Psychosocial correlates of job strain in a sample of working women. Arch Gen Psychiatry 1997;54:543-8.

26 Bosma H, Stansfeld SA, Marmot MG. Job control, personal characteristics, and heart disease. J Occup Health Psychol 1998:3:402-9.

27 Siegrist J, Peter R, Cremer $P$, et al. Chronic work stress is associated with atherogenic lipids and elevated fibrinogen in middle-aged men. J Intern Med 1997;242:149-56.

28 Brunner E, Davey Smith G, Marmot M, et al. Childhood social circumstances and psychosocial and behavioural factors as determinants of plasma fibrinogen. Lancet 1996:347:1008-13.

29 Theorell T, Perski A, Akerstedt T, et al. Changes in job strain in relation to changes in physiological state. A longitudinal study. Scand J Work Environ Health 1988;14:189-96

30 Schnall PL, Pieper C, Schwartz JE, et al. The relationship between 'job strain,' workplace diastolic blood pressure, and left ventricular mass index. Results of a case-control study. JAMA 1990;263:1929-35.

31 Theorell T, de Faire U, Johnson J, et al. Job strain and ambulatory blood pressure profiles. Scand J Work Environ Health 1991;17:380-5.

32 Harenstam AB, Theorell TP. Work conditions and urinary excretion of catecholamines-a study of prison staff in Sweden. Scand J Work Environ Health 1988;14:257-64

33 Sluiter JK, Frings-Dresen MH, van der Beek AJ, et al. Neuroendocrine reactivity and recovery from work with different physical and mental demands. Scand J Work Environ Health 2000;26:306-16.

34 Pieper C, LaCroix AZ, Karasek RA. The relation of psychosocial dimensions of work with coronary heart disease risk factors: a meta-analysis of five United States data bases. Am J Epidemio 1989; 129:483-94.

35 Green KL, Johnson JV. The effects of psychosocial work organization on patterns of cigarette smoking among male chemical plant employees. Am J Public Health 1990:80:1368-71.

36 Landsbergis PA, Schnall PL, Deitz DK, et al. Job strain and health behaviors: results of a prospective study. Am J Health Promot 1998; 12:237-45

37 Mittleman MA, Maclure M, Sherwood JB, et al. Triggering of acute myocardial infarction onset by episodes of anger. Determinants of Myocardial Infarction Onset Study Investigators. Circulation 1995:92:1720-5.

38 Siegrist J, Peter R, Junge A, et al. Low status control, high effort at work and ischemic heart disease: prospective evidence from blue-collar men. Soc Sci Med 1990;31:1127-34.

39 Reed DM, LaCroix AZ, Karasek RA, et al. Occupational strain and the incidence of coronary heart disease. Am J Epidemiol 1989;129:495502.

40 Hlatky MA, Lam LC, Lee KL, et al. Job strain and the prevalence and outcome of coronary artery disease. Circulation 1995;92:327-33.

41 Steenland K, Johnson J, Nowlin S. A follow-up study of job strain and heart disease among males in the NHANES1 population. Am J Ind Med 1997;31:256-60. 